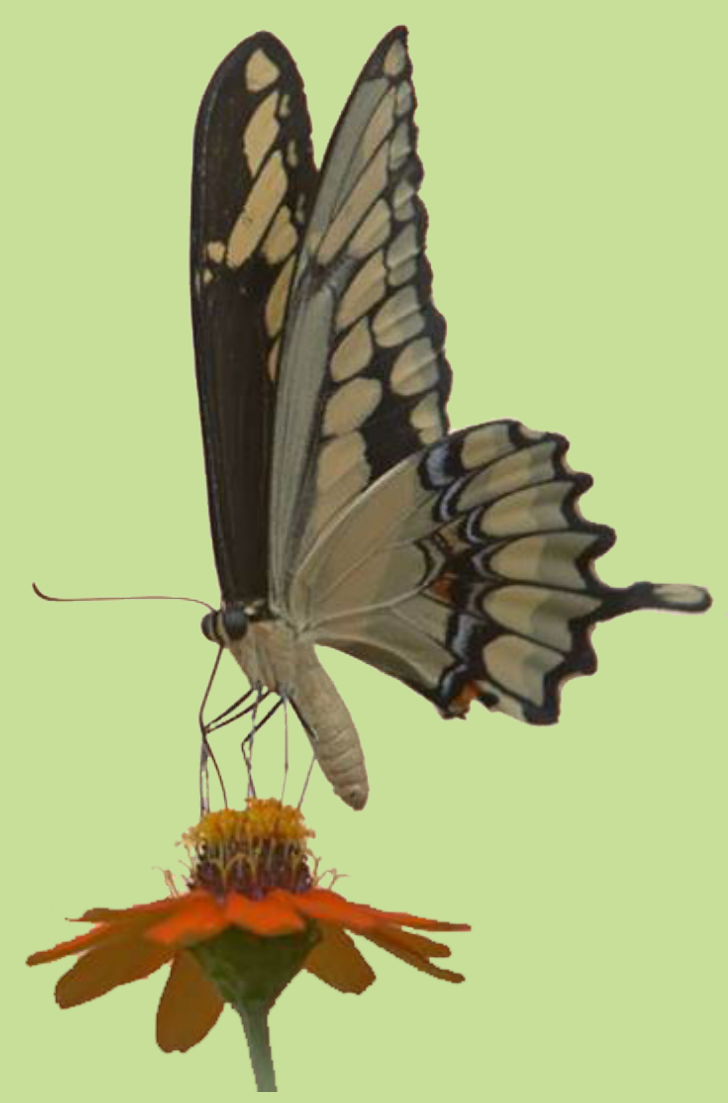

\title{
International Financial markets and Long-Term Environmental Problems
}

Erich W. STREISSLER

KIOES Opinions 1 (2013)

KIOES Opinions are published by the Commission for Interdisciplinary Ecological Studies (KIOES) of the Austrian Academy of Sciences (ÖAW). KIOES publishes current opinions of its members and staff related to topical subjects on an irregular basis in KIOES Opinions. The target audience includes scientists, policy makers and the public. Opinions expressed in this article are solely those of the author, and they do not necessarily reflect in any way those of KIOES or ÖAW.

More information about KIOES and download of KIOES Opinions at http://www.oeaw.ac.at/kioes 


\section{International Financial Markets and Long-Term Environmental Problems}

\author{
Erich W. STREISSLER ${ }^{*}$ \\ ${ }^{*}$ Austrian Academy of Sciences \\ Dr. Ignaz-Seipel Platz 2, 1010 Vienna
}

Received: 28.10.2013, published online: 19.11.2013

\begin{abstract}
Erich W. Streissler was born in Vienna, Austria, graduated as Dr. iur. from Vienna Law School and is now Professor Emeritus of Economics, Econometrics and Economic history at the University of Vienna. He was distinguished Austrian Visiting Professor at Stanford University and frequently at Oxford University. He is a member of the Bavarian, the Hungarian and the Austrian Academy of Sciences.
\end{abstract}

\section{World Financial Markets Recently}

1.1 Economics is a quantitative science in two dimensions: money and time. Thus, in analysing world problems pure economic analysis has to leave out everything that does not depend on money and time. Economic analysis is therefore always only partial analysis.

When international capital movements are completely free - and that has been the quasi-constitutional case for EU-Europe since only 1990 and for the USA, Canada, Australia and New Zealand since about the same time or even earlier - international financial markets behave nearly rationally, i.e. they are almost exclusively determined by the uses of money over time.

The characteristic properties of free financial capital markets were already described by Th. Mun, England's Treasure By Forraign Trade, written with the intent of expressing the international limitation of the power of King Charles I and published by Mun's son in 1664 for the returned king Charles II. The king (eventually: the government) has no power either of setting the exchange rate of the domestic currency to foreign currencies or of setting the interest rate (thought to be internationally determined). Thus, with free capital movements, already then assumed as a matter of course, the king (the government) has no influence over the two critical prices: the exchange rate and the interest rate. Governed by those prices the quantity of foreign exchange drifts back and forth in the current and the capital accounts, determining the accumulation of "England's Treasure" via exports and imports on the one hand and capital movements on the other.

"Kings" in the $17^{\text {th }}$ and $18^{\text {th }}$ centuries and governments and/or large international banks in the $21^{\text {st }}$ century did not and do not at all like the idea of being nearly powerless on financial markets. They are nearly powerless because, of course, they are themselves actors on free international markets, but their funds are usually quite limited relative to the total funds moveable on free international capital markets. At best, they can exercise some influence if and when private actors on financial markets are more or less in quantitative equilibrium and especially if they are rather uncertain how interest rates and exchange rates are going to change. Likewise, governments and large international bankers can exercise some influence at best in the short run only, and, in so-called "crises", not even then. Long-term attempts (as made repeatedly) to falsify interest rates and/or exchange rates in the interest of particular groups tend to result in large international bankruptcies. The attempts of the French kings during the $18^{\text {th }}$ century ended with the bankruptcy at the beginning of the 1790s in the French Revolution, and the attempt in particular of Alan Greenspan in the 2000s ended in the huge American banking and government bankruptcy of 2007-2009.

1.2 Not untypically, France's bankruptcy in the revolutionary early 1790s was due to the fact that France had had to pay, the whole century long, twice the interest rate of its main competitor Great Britain, so that by the late 1780 s her national debt cost her 
about $75 \%$ annually of all government revenue. ${ }^{1}$ (The French people, not understanding finance, attributed the bankruptcy to the expenses of the Court - which were actually quite small). In addition, France had lost each of her $18^{\text {th }}$ century naval wars, which were extremely costly. ${ }^{2}$

The bankruptcy of the 1790s brought the expropriation of the real estate of the French church and that of large parts of the aristocracy and also hyperinflation of the currency. The great US-American bankruptcy of 2007-2008 actually was not much different from the French one 215 years earlier: It was due to the government initiative of first the Clinton administration (1993-2001), continued by the G.W.Bush administration (2001-2009), to increase via easy credit the percentage of private home ownership, eventually amounting to a full $100 \%$ of credit for the already bloated purchasing prices for newly built homes. As housing prices had increased and sales fees also were large (the sales agents being the only ones to profit), houses were eventually sold at about double their actual value so that a crash of extended house credit became inevitable. The crash occurred during the summer of 2007 up to the first quarter of 2009 - one half of it was due to irretrievable mortgage credits and the other half to other bank credits. But actually those private credits were at base governmental or fiscal credits and the failed credits were in the end largely taken over by government agencies, Fanny Mae and Freddy Mac, and by the federal budget: US public indebtedness doubled from 2008 to 2012 to about $110 \%$ of GDP [gross domestic product]. Government financial involvement was largely due to the decisions and activities of one pivotal figure, Alan Greenspan, governor of the Federal Reserve from 1987 to 2006. Explicitly stating that the huge US current account deficit of up to $8 \%$ of GDP, due to a government budget deficit of up to $6.5 \%$ of GDP, was the least of his sorrows, Greenspan kept stimulating the economy during the Bush administration. Adroitly, he retired prematurely at the end of January 2006 , excusing himself with his age of 80 , but actually one and a half years before the inevitable crash.

1 See Th.J. Sargent, F.R. Velde, "Macroeconomic Features of the French Revolution", Journal of Political Economy 103/3 (1995), pp. 474-518.

2 She lost about 60 battle ships in battle and about 100 altogether, each of them costing some 30.000 pounds or about ten times as much as the typical large textile factory employing 300 people, i.e. altogether the capital of a thousand factories.
This came in the summer of 2007, climaxing with the bankruptcy of the largest financial firm in the USA, Lehman Brothers on September 15, 2008.

1.3 International financial markets are ruled by their actors' expectations about money and time. With very few exceptions, US-American theory considers financial markets as having a uniform demand for one central asset, US dollars on the internal US financial market, which is passively financed by foreign actors via the US current account. Furthermore, if there are shifts in demand, rational expectations are thought to rule. This means that if there is only one, unique rationality the world consists of only one actor, shifting expectations immediately and uniquely.

This very primitive one-actor-one-asset-model who is this actor by the way: is it, as sometimes assumed, the US government or the uniformly acting US banks? - also assumes one single time dimension, i.e. "now". Actually, under present conditions, and since the years 2000 or 2005, this primitive model has not been such a bad simplification: At present the US current account deficit of 425 billion Euros is passively financed (notionally) to one half by Germany (237.6 billion) and one half by China ( 224.8 billion) - the largest, though much smaller other current account deficits above 50 billion dollars being those of India (93.4 billion), Great Britain (91.5), Brazil (70.0), Canada (62.3), France (61.3), and Australia (51.1), all these summed up still smaller than that of the USA. This primitive model is at present a good simplification and may continue to be so as long as there are no large shifts in demand on the international financial markets (supply being even more stable). Demand shifts take long to be realised by the different actors and the international financial market is then for long periods out of long-run equilibrium and progressively adjusting. This was so in 2008 and 2009.

While the real rate of return on "safe" financial markets, i.e. financial markets of reliably paying governments, as historically for Britain since the 1730s, used to be 3 to $3.5 \%$, nowadays - with the oversupply of funds over demand - the safe rate has now reached $1 \%$ on good private funds, $1.5 \%$ on 10 -year government bonds and 2.5\% (end-June 2013) on US government bonds. The much higher rates of returns for investment with private debtors, or the $4.14 \%$ that Italy has to pay, and the $4.46 \%$ that Spain has to pay on 10-year government bonds, are due to the risk of 
non-repayment. Thus the degree of risk experienced is the central explanatory variable: differences of return.

While the Nobel Laureate Paul Krugman thought the standard international trade model of explaining trade by different capital costs (interest rates) and labour costs is now obsolete because with free international capital markets interest rates would all equalize worldwide, the Nobel Laureate Robert E. Lucas Jr. argued that this is not so: The different degrees of riskiness, both of private investments - less developed economies produce many raw materials with cyclically highly variable demand over time and also labour there is much less disciplined and reliable - and in particular also the riskiness due to the public dominance over private supply, lead to much higher rates of interest on the financial markets of less developed economies. He argued this in his important article "Why doesn't Capital Flow from Rich to Poor Countries?"3

1.4 Thus, financial markets are dominated by expectations about the value of money and expectations about time and consequently by the changes in such expectations. For the last quarter century these expectations about reasonably safe returns have to be long-run ones, typically, at least over five to ten years and even longer periods, being represented by the returns on 10-year government bonds of "safe" debtors. Expectations of each individual will typically be for a mean price, i.e. interest development with a variance around that mean. This subjective probability distribution will be either one of risk in its precise sense, i.e. expectations covering all expected states of the world together with the probabilities of the realisation of each one of these states; or much more likely one of uncertainty where the possible states of the world and their probabilities are not fully known. While there thus is a marked variance of expectations for each actor, there is also an important variance between actors. Alan Greenspan has stated that even the possibly best-informed financial actor, the US Fede-

3 American Economic Review, PP, 80 (1990), pp. 92-96. In fact, his argument is slightly different: He explains differences in returns in developed and underdeveloped countries by differences in human capital and an external economy: production which he thinks is due to monopoly power in the investing "West" and to effects of public policy, while I replace by now implausible monopoly power by high private production risks, thus altogether the riskiness of investment, for short. ral Reserve, is even for the short-period forecast of one half year constantly hovering between assumptions of risk and uncertainty. ${ }^{4}$ During and after the Great Crash of 2007-2009 the degree of uncertainty for actors has much increased and actually has staid high since then, in spite of the constant overoptimistic forecasts of US banks. Before 2008 US banks often lent up to 40 or even up to 80 times the expected future asset value, which assumed both the value of the asset, on which the loan was given, could be forecast precisely - actually it was thought that the asset value of securities could only rise over time - and also that their variability would be extremely small. Actually, during the last phase of the boom, 2005-2007, many US banks had lent out so-called "subprime" mortgages on private homes to debtors who did not contribute anything at all to the purchase price, the loan being $110 \%$ of the then house value - i.e. it was assumed that house prices would rise rapidly still further, an increase that never came. House prices then fell to two thirds of the assumed value at the time of sale, implying that banks lost about $40 \%$ of their loan value, and that only if the bank was willing to become immobilized on the houses that had reverted to it, not selling them off rapidly once more. Since 2008 banks have been trying constantly to get people to invest in international assets, but since 2008 those have actually had low and highly variable, i.e. risky, returns.

I am quite proud to have been the only economist in the German language area to have correctly forecast, already in 2002, that the best return over the entire period 2000-2012 could be achieved by "investing" in a medium-term savings account, denominated in one's domestic currency. Other investments may have had a slightly higher average rate of return, but more than the difference would have to be spent on the fees charged by the bank selling those assets. Thus, such riskier investments would only be good for the bank selling the asset (because of the bank fee charged on entering the investment), but not at all for the final investor. Actually, in the last fifteen years European banks had stimulated many investments that would be highly unprofitable for the average investor, but highly profitable for the banks: They sold investment opportunities in financial assets for very high fees, never clearly publicized, leaving the

4 Alan Greenspan, "Risk and Uncertainty in Monetary Policy", American Economic Review 94/2 (2004), pp. 33-40, here pp. $36 f$. 
asset price risk and/or the rate of return risk with the private investor. The potential investor was advised to invest, against his actual risk preferences, in the riskiest investment opportunities, i.e. in long-term assets denominated in foreign currencies, highly variable in their relative prices. Why? because those meant the highest fees for the bank.

1.5 Financial markets are dominated by more or less rational investment decisions as to money, the investment being by now international and determined by expectations of different investors reacting at different speeds to differently seen expected asset prices. To a large extent, financial markets are at present dominated by the US market, which, influenced by the American banks, appears to be still too optimistic in expectations about the rates of return on financial markets. The peak of US optimism, however, and the low point of returns seems to have been reached around April 2013, returns in the USA since then having by now (i.e. end of June, 2013) already markedly increased (from 1.7 to $2.3 \%$ for 10 -year government bonds). But world finance is still dominated by a US current account deficit of 425-475 billion Euro (figures around April 2013), notionally financed in more ore less equal parts by Germany and by China. Basically, not much has changed over the last 30 years, apart from the fact that 20 or 30 years ago the US deficit had been financed in more or less equal parts by Germany and by Japan.

What is not sufficiently realised, particularly in the USA, is that the long-run economic growth perspective for GDP for developed nations is now a growth rate of only about $1 \%$ per capita a year; and for material production, i.e. excluding services, of $0 \%$, meaning that at best it will be stationary. The high point of world material production was reached around 2005. Especially world food prices had then reached their low point and have risen since then, with ups and downs, and the same is true of energy prices. The USA, which at present have an (overestimated) boom in new types of domestic energy production, underestimate the increasing scarcity of food and raw materials - a fact that every Austrian housewife and every motor car driver will confirm from their price experiences. The USA, too, will have to learn that those price increases will continue in the long run. They are due to the fact that oil and gas reserves will be more and more exhausted, all substitutes being more costly, and to the fact that climate change will change and possibly reduce agricultural areas (because of both aridity and severe flooding and because some new forms of energy production will require large areas of land).

Of course, it is not only the efficiency of financial markets that determines the costs of a developed economy. The quality of "services" in general is of considerable importance. But in terms of an economy's human capital, it is above all the efficiency of the health and the education sectors that count. In the USA health costs gobble up about one sixth of national income, while in Austria they are not much higher than $10 \%$. As US federal health expenditure leaves out a large part of potential beneficiaries, US health costs are by efficiency units twice as high as Austrian ones. This is due to the fact that US health services are provided much more for the profit or income of health providers while Austrian public health services still rely somewhat more on the spirit of altruism and idealism of the caring personnel. As to education, two examples must suffice: In Austria education is strongly income oriented and above all dominated by the teachers union, in Finland it is guided by a high ethic: only the best students are allowed to become the teachers of the next generation.

1.6 When we look at the sources of national income and product over the last 20 years within EU-Europe on the one hand and the USA, Canada, Australia and New Zealand on the other, we have first to consider the seven years from 1993 to 1999 with peak annual growth rates of five to even seven per cent. Those high growth rates were largely misunderstood in the USA, and particularly by their banking sector, as New Age normalcy instead of as the peak of a cyclical boom. In the USA the boom was also misunderstood as one of the whole economy, while it actually was a boom of the banking and financial sector only.

The US industrial sector (the sector of material production) was actually coming more and more under destructive competition from rising East Asian and South Asian producers. In the USA, Canada, Australia and New Zealand and in EU-Europe, particularly in Germany, Finland, the Netherlands, and Austria the years 1995-1999 have to be seen as the peak of the fifth Kondratieff boom of waves of innovations since about 1790 . These Kondratieff waves last altogether about 40 years each and comprise in their peaks the bunchings of many different innovations, followed by periods when innovations of then alrea- 
dy "old" techniques have been largely exhausted, i.e. by periods of near-stagnation.

The period 1995-1999 was unusual, ${ }^{5}$ however, in the sense that there were then not several big innovations, but only one, that of the computer hardware together with its new applications, personal computer software. Furthermore, this boom was unusual in as much as computer innovations proved to be strongly capital saving instead of capital using; furthermore, computer innovations spread very rapidly because they were so cheap. In contrast, e.g., the great innovation around the middle of the $19^{\text {th }}$ century, the introduction and the spread of steam railways, which were very costly to build - initially with slow effects, too - required very much new capital.

Computers on the other hand could be cheaply built and rapidly installed, so that the branch as a whole gained relatively little, all the advantages rapidly falling to its customers, the computer users. After the boom the most publicized and thus significant early failure of a computer-using firm in the USA was that of ENRON in 2002, but there was a large number of early failures besides. Even the paradigmatic "new" firm, Microsoft, and its paradigmatic owner, Bill Gates, instead of further increasing their property value, lost one half of it between 2000 and 2012 and thus ended with one quarter of the value normally to be expected from further average growth.

Thus the great boom of 1995-1999 was immediately followed by a period of very much lower realised growth rates, difficult, however, to estimate because not only the average social product growth rate went down substantially but also the variance of growth increased markedly.

This decline was particularly marked in the USA, but was generally denied to be happening. The common denial of a crisis led to the largest number of bankruptcies ever or at least to the largest bank crash (in a wider sense) since more than a century. This general denial of facts has a parallel in the talking down of the increasing number and intensity of environmental catastrophes. They do not enter national income accounts and therefore continue to be considered as exceptional, while actually becoming ever more frequent.

5 In a speech on December 5, 1996, Greenspan held that "irrational exuberance has unduly escalated asset values". See the same, The Age of Turbulence, London 2007, p. 177.
1.7 Quite generally, serious financial difficulties followed from 2000 onwards. The crucial question has been and is: Should government help firms, particularly those that are making the relatively largest losses (although often those were the very ones that had made the biggest gains earlier on); or shouldn't government rather help the general public, i.e. in democracies the average voter, especially in case of serious financial losses for the entire economy?

This crucial question is far from having been answered unequivocally, but continues to be the subject of heated debates, nationally and internationally. The answer that individual economies will find for this question will determine to a large extent how much they will have to spend on matters other than saving their banks, on important matters like research, development and innovations with a view to their future - a future of dwindling resources as to energy and foodstuffs.

Jeff Madrick ${ }^{6}$ has stressed that in the USA over the last years mathematicians have been in high demand by firms. They receive about three times higher salaries than general managers or economists. Mathematicians will tend to analyse highly complicated economic constellations, but - a weighty "but" - will restrict themselves to basically stationary systems. ${ }^{7}$ They will therefore tend to underestimate the degree of change, in the USA as well as in Europe, of a global economy with increasing environmental costs, with climate change and with markedly increasing energy costs, due to the exhaustion of global oil resources. Typically, Americans therefore underestimate longrun energy price changes in contrast to Europeans, although this is also partly due to the fact that the USA are desperately trying to get more "self-supporting" in energy - eager to develop shale oil and tar-sands.

Lord Stern ${ }^{8}$ in Britain estimates that energy costs will increase by $1 \%$ a year. This is an underestimation, however, since Stern assumes that homogeneous economic decision takers will always take the

6 Jeff Madrick, Age of Greed, New York 2011.

7 That economies behave as basically stationary systems is the fundamental vision of Milton Friedman. See the same, "The Methodology of Positive Economics" in: Essays in Positive Economics, Chicago 1953.

8 Nicholas Stern, „The Economics of Climate Change", American Economic Review, PP 98/2 (2008), pp. 1-37. 
best decision, i.e. the least-cost development decision. In reality, though, important established energy producers will tend to impede the best, i.e. leastcost development for the economy as a whole. Thus, Americans generally tend to overestimate the possible growth rate of the economy, particularly at the beginning of each year, being regularly disappointed around April, while Europe tends to assume much lower growth. This is only to a small part due to its particular economic inefficiency, viz. high youth unemployment, especially in Southern Europe and France, but much rather to the relative rise of the top wages of $20 \%$ or $30 \%$ of qualified workers - relative to Germany and Austria - in the first years after the introduction of the Euro.

A.B. Atkinson ${ }^{9}$ has also shown that recently the US income distribution has become much more uneven - far more than in other developed economies. Most of all, US top wages have gone up. This is largely so because on the one hand US top commercial salaries have increased so much more than elsewhere, and also because of the (already touched upon) fact that the salaries in the financial sectors, most of all those of mathematicians, have far outrun the corresponding payments in other countries.

1.8 As the world as a whole is a closed economy, realised world savings have to equal realised world investments. But at least since 2000 , i.e. by now in its $14^{\text {th }}$ year, intended world savings by far exceed realised savings, and also intended worlds investments. Intended savings have thus to be reduced to the volume of realisable savings. And since for more than 30 years now the USA have been the ones to reduce realised world savings by consuming - instead of investing - them: The current account deficit of the USA is huge, at present being still 425 trillion Euro (it had been around 800 trillion in 2005-2007); and notionally China and Germany each finance about one half of this excessive consumption, as mentioned above.

Around 2000, China started to try to invest about 5\% to $10 \%$ of its huge savings (of about $50 \%$ of GDP) in foreign - most of it as short-term investment in the USA. By now, this Chinese inflow there is more like four to $5 \%$ of Chinese GDP: In spite of all attempts

9 Anthony B. Atkinson, Th.Pickety, E.Saez, „Top Incomes in the Long Run of History", Journal of Economic Literature 49/1 (2011), pp.3-71. to invest, particularly in Africa, China has not been able to stop placing large amounts of its savings in the USA, which are then consumed in the US. The USA are still able to run a - by now somewhat reduced - current account deficit of $-4.5 \%$, which apart from present-day Japan ( $-8.7 \%$ of GDP), Britain $(-7 \%)$ and Spain (per-7\%) is relatively the largest, and of course, absolutely the by far largest one in the developed world.

Thus, since the year 2000 the world has been suffering - suffering is the mot juste - from an excess of intended savings which, above all, the USA are simply gobbling up by their huge current account deficit. It took the general public long to realise that there is such an excess of world savings and that therefore interest rates had to fall correspondingly. It was mainly US-American banks, followed by European banks that clouded this issue. It is true that interest rates for credits to the public for some of the credits between banks fell markedly. But average interest rates of credit to non-bank private individuals could be kept up and also interest rates of credits to some countries like Greece. In general, however, well-established private firms did not need any investment credits because they had stocked up on funds - in fact more than necessarily stocked up relative to the lower growth rates after 2000. So it was rather the more dubious firms that had to pay higher interest rates for investment credits, which were actually higher due to risk premiums. And above all, it was housing construction credits that were thought by many banks - especially in the USA and Spain - to offer good investment opportunities, although actually they only created large capital losses of perhaps some $40 \%$ from 2007 onwards.

Only since 2011 it has been generally realised, at least by European banks, that funds were more than ample; so then interest rates fell by about $1 \%$. At present in Austria good medium term bank credit pays around $1.6 \%$, while medium-term savings accounts pay $7 / 8$ of $1 \%$, leaving only a tiny margin to the banks.

In the USA interest rates had probably reached a secular low around April 2013, starting to rise after that when it became likely that the Federal Reserve would try to stop its unlimited bank funding (at short term interest rates of only $0.2 \%$ ). Safe 10 -year government bonds interest rates, which had touched a mere $1.5 \%$, have by now, mid 2013 (The Economist June 29th), reached $2.54 \%$. This is, however, still $1 \%$ below the 
long-time normal non-inflationary rate of about $3.5 \%$ which Britain has had since the 1730s. (The $1.6 \%$ measured consumer price increase in the USA at present corresponds to $0 \%$ true domestic inflation, as the consumer price index, for well-known reasons, overestimates actual inflation by at least 1 percentage point, to which has to be added at present that some further measured inflation is due to imported price rises of foodstuffs and of energy which should be deducted for the calculation of domestically caused inflation.)

In estimating an increase in real product and in spending power a further important point has to be remembered: The USA, which always tend to look at their locally created national income, and not at the United Nations standard measures, constantly overestimate their current earning and consuming power: At present (see The Economist, June 29, p. 84), the annual increase in US GDP is estimated at $1.8 \%$; but the increase in their foreign debt, i.e. the current account deficit, is estimated at $-2.8 \%$, so that net US increase in wealth is actually minus (!) $1 \%$. For Austria, on the other hand, the estimated increase in GDP is only $0.6 \%$. But, on the other hand Austria is accumulating foreign assets, as its current account surplus is estimated at $2.1 \%$. Together these two figures would amount to a $2.7 \%$ increase in yearly gross income. (Whether the German increase with a $6.2 \%$ measured current account surplus is any larger may be doubted, because much of the German current account surplus is, in fact, a transfer at $0 \%$ interest. This has to be interpreted as a gift to other countries; and gifts, being one-sided, do not enter national income calculations, which are only the sum of two-sided transactions.)

Considering the 2000s as a whole, we have to remember that Alan Greenspan - of all people - estimated that the capital losses of the Great Crash of 2007-2009 amounted for the entire world to 40 trillion dollar or about $60 \%$ of average annual world income; and for the USA to 17 trillion or about $120 \%$ of a year's GDP. Subtracting that from the measured growth rate of domestic income and product we find a strong decline in income in the USA over the whole first decade of the $21^{\text {st }}$ century. We have to recognize that the initial estimate of the fall in domestic product a little later proved to have been somewhat overestimated, but, on the other hand we have to add on the large environmental damages in the USA during that decade - which are not included in the national accounts -, then the true average of the US economic growth rate for the 2000s was at best zero and more probably slightly negative.

The low point of energy prices and also of relative food prices was probably reached around 2005. Since then, both food and energy prices have gone up markedly. But that is not a once and for all occurrence, but much rather the beginning of a trend likely to continue, even if the USA are once more in denial because of the - probably highly overestimated - possibilities of finding shale oil or gas and using tar-sands.

Altogether peak production of natural oil has probably already been passed; and alternatives to oil will be more expensive. And the same is true of the average cost of food supply. In Austria, prices for farm products have already somewhat increased over the past years. And the increase in forestry or growing of "bio-mass" for the purpose of creating additional sources of energy is a questionable alternative for the use of land for growing foodstuffs. Climate change may cause more drought and also floods, in turn reducing food production.

Thus for the next decade and for the average of the developed world an average growth rate of about $0.5 \%$ a year seems likely at best. (Remember that for the 1990s and the 2000s Japan had an average growth rate of only $0.25 \%$.) The growth rate of Austria might be somewhat higher at perhaps $1 \%$ of $\mathrm{GDP}^{10}$ if innovative small and medium firms should succeed in finding new sources of energy (a hope recently expressed by the President of the Austrian Trade Unions, Erich Foglar ${ }^{11}$ ). In the longer run, however, we are likely to witness slightly negative average growth rates, so that, e.g. for Austria at least material social product (i.e. product without services) for the year 2050 would be about the same as at present. And as population is unlikely to increase noticeably, also social product per capita is likely to be about the same as in 2010. Further growth is likely to become ever

10 A comprehensive and critical study of Austria (as compared with other EU-countries) has just been presented by Bernd Marin, Welfare in an Idle Society? - Reinventing Retirement, Work, Wealth, Health, and Welfare, Farnham - Burlington 2013. As to a general historical survey of financial crises see Carmen M. Reinhart, Kenneth S. Rogoff, This Time is Different - Eight Centuries of Finacial Folly, Princeton, NJ, 2009.

11 Erich Foglar, "Förderung der Arbeitskraft Österreichs in Gegenwart und Zukunft", Public Lecture at the Austrian Academy of Sciences, December 19, 2012. 
more costly and therefore low or negative for environmental reasons.

\section{Long-Term Environmental Problems, Climate Change and Increasing Scarcity of Natural Resources}

2.1 The economies that were gained by the wave of computer innovations have been rather exhausted by now. What may be the next possibilities for large innovatory advances? Of course, the main innovations of the next, the sixth Kondratieff, which may be expected to peak around 2040 or even 2050, cannot be made out as yet, 30 years in advance. But two types of innovation can already be discerned.

On the one hand, there is innovation in health economics. Austria, and especially the Austrian Academy of Sciences, is at the fore here: The three large institutes of the Academy IMBA, CEMM, and CMI are leaders, costing altogether somewhat over 50 million Euro a year - to which one has to add derivative products of their research. The eventual "product" of health economics does not, however, fully increase calculated GDP as such: An increase in the life span of human beings, e.g., does not enter national product calculations.

Long-term environmental improvements or the retarding of climate change and finding cheaper substitutes for the natural resources that get scarcer all the time, do constitute typical economic innovations. As every single such innovation is likely to be relatively small, Austria is well suited to find some of them: On the one hand, we have the small and medium firms that are likely to produce such innovations in highly specialized fields. (In his lecture at the Academy Foglar gave three examples of such firms with very high $\mathrm{R} \& \mathrm{D}$ investments.) Some of those firms (all told probably 184) are, in fact, world monopolists, of which Austria has a relatively large share. On the other hand, Austria does not have the big firms in old standard production lines, which typically tend to impede innovations, because they only see harmful competition there. It is exactly the innovative type of small and medium firms that has made for a shift of industry away from the traditional core in Northwest Europe to south of the Main, i.e. to Bavaria, Austria and the Neckar valley of Baden-Württemberg.
At least up to 2008 Austria was rather hesitant to turn toward long-term environmental change and development of new resources. Such developments typically take time and require initial long-term investments, i.e. investments that do not bring in returns for many years to come. So financial capital was not at all forthcoming. On the other hand, Austria has had a comparatively (both in EU comparison and world comparison) low rate of unemployment, especially of youth unemployment; this means that a lot of young people must have been in training. In other words: Comparatively little human capital has been wasted and at least part of it was/is being improved. This may be a reason for hope that more of the existing firms develop an interest in innovation and that some new firms as well turn to environment-friendly and resource-saving production lines.

2.2 Topics relating to long-term environmental problems that should be dealt with by natural scientists are typically highly specialised. Therefore one has to find scientists willing to take up new topics in addition to their current specialization and, even more important, to get young scientists to turn to such innovative topics.

Fields in which pertinent studies should be undertaken were suggested on June 10, 2013 at a meeting of KIOES. They were

- $\quad$ organismic botany and organismic terrestrial zoology

- $\quad$ systems analysis, in particular systems ecology

- $\quad$ hydrology, in particular hydrobiology of rivers and lakes.

The following five sectors of an economy were mentioned as possible focuses of pertinent research: transportation, energy economics, agriculture and forestry, soil conservation, landscape planning and development.

2.3 In the economics of long-term environmental development the central problem is, as always, the costs it entails. By now, many developments will be taken up by commercial firms, which, after substantial investments in research and development (possibly subsidized), expect profitable production opportunities - particularly so at present when long-term real interest rates are low, making investments more 
feasible. Innovating firms in one of many hundreds of new fields can expect to become monopolists, in some cases even world monopolists. They might earn monopoly profits, though better not too conspicuously, in order not to stimulate too many would-be competitors. Other developments, especially in the field of basic sciences - developments preparatory to production technologies -, will come to fruition only if they are substantially publicly subsidized. They depend crucially on which fields, if any, public policy intends to stimulate most. Such stimulation might be important as development policy for certain new industries.

But, of course, stimulation of public research might also turn out an eventually vain endeavour. There is the famous example of Czech public research endeavours under Communism, which then cost four times more than comparable programs in Austria, but brought about at most half of Austria's effective output, mainly because personnel politics were mixed up with the research. Furthermore, the history of innovation in steel production is a warning example even in a democracy: When Austrian public policy finally came around to backing a certain presumably profitable steel making process the more rapid innovators in other countries had already creamed off all the possible profits; and in addition, the still too hasty development of a new type of steel meant that the huge ensuing environmental problems had been most dangerously ignored.

A further cost aspect has already been touched upon. Lord Stern in his plea for an environmental policy to retard global warming had calculated that the respective measures would cost only $1 \%$ of GDP a year. But he typically assumed that the entire economy would act as one actor, i.e. all those responsible would plan in the same direction. Such uniform behaviour is, however, rather unusual in a democracy. On the contrary, there are likely to be delays, inactivity and counter-effects in various branches. Therefore the total cost of any environmental policy is likely to be considerable higher.

In fact, the Association of Austria Industrialists has recently announced a strategy of preserving old and outmoded industries, a typical short-term stop-gap policy that tends to seem attractive in periods of doubtful and probably low demand. Immediately after the crash of 2008, German industry, followed by Austria, in fact installed a counter-productive policy:
In order to stimulate traditional automobile production, which for environmental reasons should have been reduced and possible even phased out, it was decided to scrap certain old, environment-damaging models of cars. Most of them were not scrapped at all, however, but sold to less developed countries, especially in Eastern Europe, so that the effect they had on world environmental damage was hardly reduced, while the "new" (traditional = gasoline using) cars actually increased environmental cost.

2.4 Let us discuss the economics of long-term environmental development in the five sectors mentioned in 2.2 .

First to consider are future changes in transportation. They will be cost-determined. Mineral oil is running out and shale gas and other forms of gasoline cannot as yet be directly used in automobiles. Innovatory changes will make gas better usable in the future. But by 2050 energy to be used in road traffic may easily be three to four times as expensive as now: Public transport will once more have to come to the fore, especially in urban areas - and the more, the larger the conglomeration. Private cars are likely to be used for weekend travel and/or in much increased car sharing for going to and from workplaces. A considerable part of gainful work, however, will probably become home-centered in the meantime.

Energy economics is becoming of vital importance. The development and use of sources of more and more renewable energy will mean that water power, already now very important in Austria, will be even more harnessed to energy production. Wind power will have to be developed much more intensively, perhaps with the help of public subsidies. The drop in elevation at the Eastern end of the Alps is well suited to be used for wind power production. The possibilities of collecting solar energy in Austria have not been thoroughly studied as yet; there may be quite a potential there. Last, not least, the increasing percentage of woodland may also provide a source of renewable energy.

This brings us to agriculture and forestry. Forests as important sources of environmental-friendly building materials and possibly as sources of energy are becoming more and more attractive investment opportunities. More rapidly growing trees to be planted in plains are being searched for. But the millennia old forest cover of the mountainous areas of Austria is 
likely to remain the most economical source of wood. Over the past decades, the average temperature in the alpine areas of Austria has risen more than average world temperature, i.e. by about $2^{\circ} \mathrm{C}$ instead of only $0.8^{\circ} \mathrm{C}$. That is to say, forests will grow to $200-300 \mathrm{me}-$ ters higher up than over the last centuries: additional forests will start to become usable in formerly unproductive mountain areas. Woodland is thus likely to increase without the opportunity cost of losing some other production. For this reason alone forests are likely to exceed $50 \%$ of the usable land area of Austria soon.

Land resources for dairy farming are likely to stay more or less the same, while the productivity increase in their use is likely to continue. With rising temperatures worldwide and thus with longer periods of aridity, conditions of grain production, however, may markedly deteriorate. In particular, grain foods are going to become three to four times as expensive as now, and meat of grain-fed animals will do so as well. As is well known, the production of beef is highly inefficient as to land use and energy use. Future generations will therefore have to turn more and more to consuming soy beans and other pulses. The demand for "organically grown" food also tends to increase food prices.

Soil conservation and landscape planning and development ask for long-term economic perspectives. Problems might arise here because of a short-term orientation of land use - in agriculture, in particular in industry, as well as in housing. The end product of short-term overuse of soil is likely to be wasteland. In England, the "first industrial nation", as well as along the waste strip along the former "Iron Curtain" throughout Europe, un-thought of developments have occurred in wastelands: Because of the complete absence of fertilizers, some such areas have become a reservoir of rare plants, which had been destroyed in other, "cultivated" areas.

To a large extent soil conservation is an issue of longterm property rights. Builders who wish to resell soon are typical "sinners" as to long-term soil conservation, and many small communities are politically dominated by the interests of private builders. Landowning farmers, particularly in Austria, tend, however, to have a more long-term and thus preserving perspective. Happily we do not have the sometimes catastrophic "wild" build-ups of many less developed economies - due to the absence of individual property rights.

Very important is the energy consumption of the industrial sector. Close to $40 \%$ of all energy use is by industry and another close to $40 \%$ by road traffic. With motorcars, the most important issue is that the rapidly rising cost increases of natural oil and gas be fully passed on to the oil and gas consumers. Of course, they will ask for subsidies, but such wishes will have to be ignored. This is the only way to bring down private use of motorcars. If cars that use much energy were additionally taxed, once more an already now plausible policy measure, no further policy initiative would seem to be necessary.

But in the case of industry the total energy cost rarely exceeds $5 \%$ of cost, and is frequently much less with the important exception of steel and aluminium production. Here, the likely howls for subsidies in case of progressive cost increases would have to ignored: For its survival, industry depends on its knowhow and not on non-wage costs. Actually, in many cases that would not at all mean losing most of the firms, as planning and sales costs are much more important than mere material production. (After 1990, there were cases, in fact, where Austrian firms shifted production across the borders to Slovak or Hungarian locations, then "imported" the finished products to Austria and, before marketing them, just marked up the price by $100 \%$, thus turning the product costwise into a "local" = Austrian one.)

Thus the proportion of energy consumption by industry will have to be very substantially reduced. Planning and sales efforts consume little energy; and industrial innovation is going to be mainly energy saving. When both transport and industry require mainly only renewable energy, the aim of not letting global temperature increase by more than some two degrees can be more or less achieved, as far as Austrian energy use is concerned. And the necessary innovatory types of industries are likely to use energy only sparingly.

The most important one of all vital resources is clean water - becoming more and more of a scarcity worldwide. International conflicts as to water use are already simmering, e.g. in the Middle East. Mountainous Austria is particularly rich in water, but the legal situation (water law and individual water rights) is not unequivocally clear: a conflict between federal and 
local government agencies is lurking. There are various unanswered questions, e.g. as to rights of springowners or the obligations of agents using running water for private energy production.

In all of the above sectors, preservation cannot be achieved by producing more of the same, but by courageously exploring possibly cost-effective avenues of change.

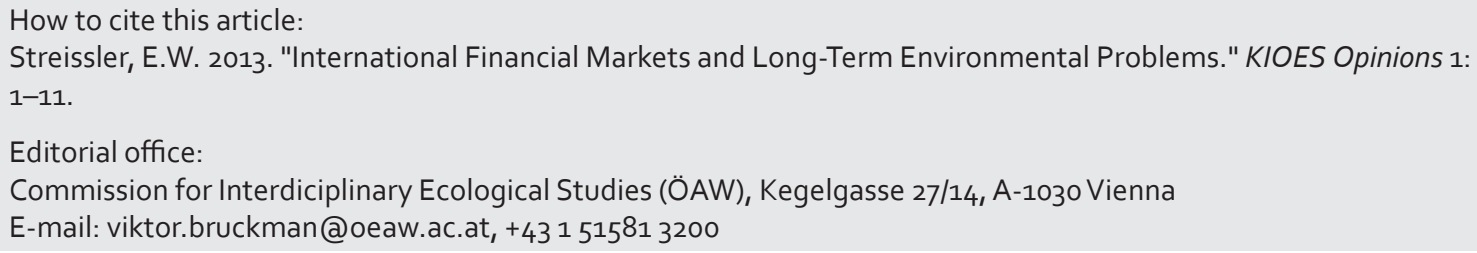

